\title{
BioVersys Works to Bring Antibiotic Resistance to an End
}

\author{
Marcel Tigges*, Marc Gitzinger*
}

\begin{abstract}
BioVersys, founded in 2008, is working on bringing a technology for screening and for the development of 'transcriptional regulator inhibiting compounds' (TRICs) to patients in order to overcome antibiotic resistance. The co-founders share their view on what makes successful scientists pursue a career as start-up entrepreneurs rather than a classic academic career. They describe the history and milestones of their company, and how their everyday work differs from that of peers in an academic or industrial research setting.
\end{abstract}

Keywords: Antibiotic resistance · BioVersys · Life science start-up · Nosocomial infections · TRIC · Tuberculosis

\section{BioVersys - the Founders' Backgrounds}

Marc Gitzinger is CEO of BioVersys. After studying molecular biology and biotechnology at the University of Freiburg (Germany) and the University of Queensland (Australia), he did his PhD in the group of Prof. Fussenegger in the Department of Biosystems Science and Engineering (D-BSSE), ETH Zurich, in the Basel D-BSSE labs.

Marcel Tigges, today CSO and head of Research and Development at BioVersys, finished his $\mathrm{PhD}$ in biotechnology in the same group in 2008, and was awarded the ETH Medal. He holds an MSc in Molecular Biology from LMU Munich, and did his master thesis at the Max-Planck-Institute for Psychiatry in Munich, where he also worked in parallel as a research associate from 2000-2004.

\section{Innovative Science - the TRIC Concept to Fight Antibiotic Resistance}

During their $\mathrm{PhD}$ studies, Marc Gitzinger and Marcel Tigges showed that transcription factors play a role in enabling pathogens to resist antibiotics. Their work led to a technology for screening and for the development of 'transcriptional regulator inhibiting compounds' called TRICs. TRICs turn off genes that would normally initiate an antibiotic reaction cascade in a bacterial pathogen, and therefore disrupt the work of transcription factors that enable bacterial resistance (Fig. 1). The pathogens no longer recognize the antibiotic attack. Thus antibiotics that have become ineffective due to bacterial resistance will once again be able to kill the pathogens. BioVersys' work getting TRICs to market is based on a lot of classic chemistry, which is why BioVersys contracted a team of chemists to complement its internal expertise in micro- and molecular biology.

While Marcel Tigges tinkered with the idea of pursuing a classic academic career that would potentially lead to a professor- ship, Marc Gitzinger always had the clear goal of a career in the life sciences industry, rather than in academia. Alongside developing his scientific expertise while studying, Marc gained insights into intellectual property rights at the patent office of Ernest T. Freylinger SA (Luxemburg) and Joachim Stuercken GmbH (Germany), and initial business insights as an Associate Intern at McKinsey \& Company. In parallel to his studies he also participated in several business courses and business plan competitions.

The daily exchange, discussions and interaction between Gitzinger and Tigges as PhD students in the shared lab generated many innovative scientific ideas. It also proved a fertile ground for what they report gradually became a logical next step: the plan to co-found a company to bring their scientific concept to patients.

In 2008 they co-founded BioVersys, and won EVA - the Basel life sciences start-up agency - as lead investor and valued sparring partner and coach for the first challenging steps of the company's life. BioVersys then generated a total of CHF 2.5 million in seed money from private investors, mainly from the BioValley

*Correspondence: Dr. M. Tigges, Dr. M. Gitzinger

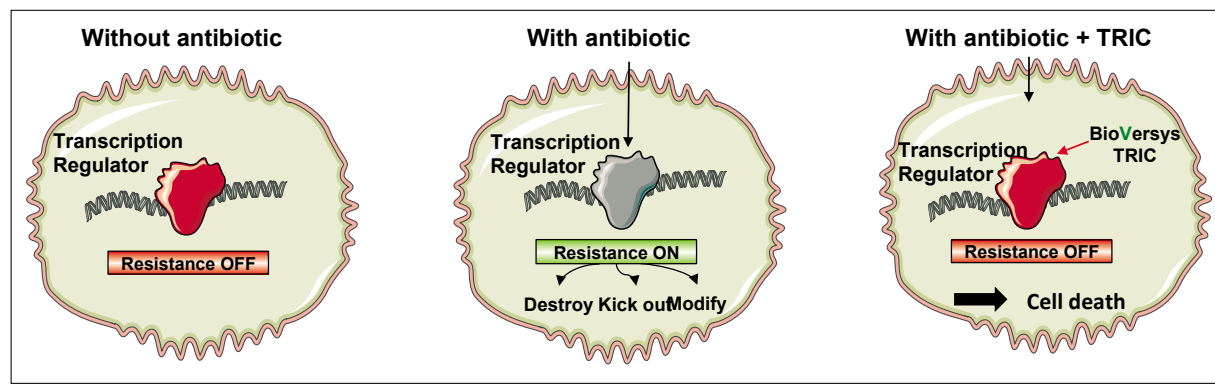

Fig. 1. TRIC (Transcriptional Regulator Inhibitory Compound) mode of action. BioVersys develops new chemical entities that demonstrate targeted interference with transcriptional regulators (TRIC). By binding this target family, TRICs have the ability to affect the machinery of bacterial resistance to antibiotics and thus have the potential to restore the effectiveness of these antibiotics. 
Business Angels Club BioBAC in Basel that is closely associated with EVA, and they also found a home for their lab in the Technologiepark Basel.

The BioVersys TRIC approach targets intracellular pathways responsible for bacterial resistance, and is based on the identification and inactivation of bacterial resistance factors in relevant pathogens. ${ }^{[1-4]}$ One of the lead compounds, BDM-31343, has already exhibited excellent characteristics as it allowed to boost the sensitivity of Mycobacterium tuberculosis to the classic antibiotic prodrug ethionamide in a mouse model. Based on the successful identification and application of BDM31343, BioVersys is currently expanding its screening and compound portfolio to nosocomial bacterial strains (e.g. Pseudomonas aeruginosa, Enterococcus faecium and Acinetobacter baumannii) that contribute not only to the high costs of in-patient care, but also cause a high number of casualties worldwide.

\section{BioVersys - Intrinsic Motivation and a Path Paved with Prizes}

Marc Gitzinger laid the basis for his business expertise with a series of preparatory courses from the Swiss venturelab program. After a semester course called venture challenge, he participated in the intensive venture plan program and venture training, and was a member of the Swiss National Team that competed in the venture leaders program in Boston, MA, USA. He is convinced that the venturelab program is an ideal platform for anyone thinking about founding a high-tech company, as the courses not only teach basic business knowledge, but also convey the 'founder's spirit'.

In 2008, shortly after formally setting up BioVersys AG, Marc Gitzinger was selected as one of the winners of the Swiss Venture Leaders Prize, an entrepreneurship award organized by the IFJ and Ernst\&Young. Together with Marcel Tigges he completed all three stages of venture kick, winning all three stages with prize money of CHF 130,000 in total. As well as the prize money, tips from coaches and networking in venture kick helped BioVersys to pick up speed and gain extra know-how in entrepreneurship, as the requirements for successfully completing the three stages of the venture kick program become increasingly stringent and demanding along the way.

In 2009 Dr. Wilfried Weber and BioVersys won the Swiss TB award. In 2011, BioVersys won the Swiss Technology Award for outstanding achievements in innovation and technology with aboveaverage market potential and good growth prospects, and it also won the Life Sciences Prize 2011.

In spring 2014 BioVersys announced a collaboration with GlaxoSmithKline (GSK) to develop a preclinical candidate against tuberculosis (TB), co-funded by the Wellcome Trust, in close collaboration with a research consortium of leading scientists in $\mathrm{TB}$ research and drug discovery from the Institut Pasteur de Lille, Université Lille 2, Institut National de la Santé et de la Recherche Médicale (INSERM) and Centre National de la Recherche Scientifique (CNRS).

Tuberculosis (TB) is caused by Mycobacterium tuberculosis, and the leading cause of death from a bacterial infectious disease globally. The WHO reports nine million new cases of active TB every year, and it is estimated that about 1.6 million people die from the disease annually.

The joint project will use BioVersys' award-winning innovative TRIC and leverage the expertise resulting from the long history of TB research in Lille to reactivate the efficacy of Ethionamide activity, a concept that the groups in Lille have been advancing since 2001. The teams of Professors Nicolas Willand, Alain Baulard and Bénoit Deprez have significantly contributed to the compounds relevant to the project and were the first to discover the target regulator in TB. The Wellcome Trust is co-funding the development activities as part of a pre-existing collaboration with GSK to find treatments for diseases in low-income countries.

Marc Gitzinger and Marcel Tigges agree that success as the main trigger is a strong intrinsic motivator to get bench work results out into the community for the benefit of patients - to leave a legacy that goes beyond academic publications. They are equally adamant that it needs a strong team to solve problems and overcome challenges in both science and business. As in every successful sports team, they say, it does no harm if the start-up team members are diverse in terms of personalities, strengths and preferences for either science or business. To make a difference it is crucial that all the members of a small founders' team have a clear idea of the role they play, and that they play it with energy, tenacity and a high threshold for frustration. Founders need to multi-task and they must be willing to work very long hours at times.

\section{Start-ups - Common Clichés, Misconceptions and Wrong Impressions}

At BioVersys, Marc Gitzinger is Chief Executive Officer, Marcel Tigges is Chief Scientific Officer. They emphasize that there are many misconceptions with regards to the distribution of duties and tasks in a young entrepreneurial team. While CEO Gitzinger spends a large proportion of his time networking with investors and business partners, CSO Tigges invests equal amounts of time networking with scientific experts and potential collaboration partners. Many of the daily tasks do not differ significantly from those of colleagues pursuing a classic scientific career. In academic or industry research labs as well as start-ups, there is the same need to continuously advance the science, plan, write grants, network with colleagues, publish, and lead and coach their teams. In life sciences they also need to cope with long product development timelines compared to other industrial sectors.

However, during the first phases of a start-up, new challenges besides running the core business and advancing science will arise, including organizational and/or infrastructure problems, legal challenges, informatics problems, people management, discussions with investors, and managing financial and scientific collaboration and partnerships, to name just a few. One of their main challenges at BioVersys is to keep the lab routine running alongside tackling everything that simply crops up, and to focus on continuously advancing the science through development of new assays and experiments in parallel to the many other activities

The problems that young entrepreneurs encounter are mostly related to doing things for the first time. This means young entrepreneurs must be willing to decide quickly and take creative action in areas where they have no experience in terms of the challenge, nor sound expertise in that field. As a consequence, they must often accept that they could have done better, and then immediately apply what they have learned to prevent a repetition of the same error.

\section{Follow Advice - but Make sure you Pursue your own Way}

Learning means networking as much as possible, listening to the advice of 'old hands' with lots of business experience and/or scientific expertise, and implementing the feedback as quickly as possible. Investors and advisers are approached by a great many people seeking money and/or advice, so it is crucial for entrepreneurs to be able to 'sell' their business idea effectively in just a few sentences. When Marc Gitzinger applied his BioVersys elevator speech literally while in an elevator with one of the first investors, he was told to rethink the initial BioVersys strategy of aiming to find new antibiotics in parallel to advancing their innovative TRIC tech- 
nology. Gitzinger and Tigges discussed this feedback and implemented it immediately. They abandoned the idea of finding new, yet unknown antibiotic molecules to fight pathogens in favor of putting all their available resources in the proof of concept for TRICs.

Letting go of one's own ideas, and in later phases letting go of things that turn out not to work as expected is often hard, and there is no golden rule for finding the right moment to discontinue activities compared to waiting for a breakthrough. One of the biggest challenges the founders of BioVersys cite in this regard is finding the balance between staying true to their personal strategy and roadmap for their young company and taking their own decisions rather than blindly following every new piece of advice, idea or suggestion they hear along the way.

\section{Create the Right Team and Pay the Going Price for it}

Another important recommendation Gitzinger and Tigges have for anyone with an interest in founding their own company is to ensure that everyone involved in the start-up receives a salary that satisfies their own needs and that of their families. They are convinced that working long hours for almost no or literally no money, as often reported in what they both call "wild west romanticism' about start-up founders, will not work out in the mid- and long term. The dissatisfaction that accompanies a 'starvation diet' as well as exposing their families to financial stress distracts entrepreneurs from successfully advancing business and scientific goals. While start-ups cannot pay salaries that can compete with those in life sciences blue chip companies, it is nevertheless important to invest in a good team.

Growing the team with good people can be challenging for entrepreneurs in terms of aspects beyond the financial investment. To ensure success, entrepreneurs must look for people who are better than they are themselves. BioVersys recently grew the team by employing an experienced chemist as VP Medicinal Chemistry.

Peter Sennhenn has a track record of more than 18 years of industrial experience in drug discovery with a broad range of preclinical research programs and international project teams. Before joining BioVersys, he held positions in medicinal chemistry at Boehringer Ingelheim in Germany and Austria, as director of medicinal chemistry at GPC Biotech and head of medicinal chemistry at Proteros in Martinsried (Germany) and just recently as a self-employed consultant in translational medicinal chemistry for academic organizations. His key expertise is in the area of structure-based drug design, lead identification and multidimensional lead optimization, with a strong background in organic synthesis.

BioVersys is proud to have attracted him to lead its medicinal chemistry that is being performed by a team of external chemists from a contract research organization. Sennhenn says he is excited to join BioVersys, an award winning company. In contrast to being a small cog in a big machine, he is now heading up medicinal chemistry programs investigating therapies for diseases caused by drug-resistant bacteria - an area of high unmet medical need. He says that his personal goal is the benefit that others draw from his work. So heading up the chemists working for BioVersys satisfies both his own ethical standards as well as his fascination for good science and challenging chemistry.

\section{Recommendation for a Professional Career}

Despite the challenges and a good dose of frustration along the way, founders Gitzinger and Tigges, VP Sennhenn and the lab staff also have fun and enjoy working for BioVersys, not least because so far the company is doing very well. They appreciate the opportunity to learn fast on the job, and do things the way they think best, rather than just following a supervisor's instructions - even though this sometimes means learning things the hard way.

Received: September 30, 2014

[1] T. Grau, P. Selchow, M. Tigges, R. Burri, M. Gitzinger, E. C. Böttger, M. Fussenegger, P. Sander, Antimicrob. Agents Chemother. 2012, 56, 1142.

[2] M. Pieren, M. Tigges, Curr. Opin. Pharmacol. 2012, 12, 551 .

[3] W. Weber, R. Schoenmakers, B. Keller, M. Gitzinger, T. Grau, M. Daoud-El Baba, P. Sander, M. Fussenegger, Proc. Natl. Acad. Sci. USA 2008, 105, 9994.

[4] N. Willand, B. Dirié, X Carette, P. Bifani, A. Singhal, M. Desroses, F. Leroux, E. Willery, V. Mathys, R. Déprez-Poulain, G. Delcroix, F. Frénois, M. Aumercier, C. Locht, V. Villeret, B. Déprez, A. R. Baulard, Nat. Med. 2009, 15, 537.

\section{My vision is one of a Health Valley in the Lemanic Arc, we have a lot to offer. We would like the private sector to invest in this concept and support this long tradition of shared research projects. 99}

